\title{
Cytological profile of Pap smears in a tertiary care hospital of West Bengal, India
}

\author{
Nandini Bhaduri Bhattacharyya ${ }^{1}$, Dinobandhu Naga ${ }^{2}$, Aditya Prasad Sarkar ${ }^{3 *}$, \\ Sabitri Mandy ${ }^{1}$, Purna Chandra Das ${ }^{4}$
}

\begin{abstract}
${ }^{1}$ Department of Pathology, Bankura Sammilani Medical College, Bankura, West Bengal, India
${ }^{2}$ Department of Medicine, Bankura Sammilani Medical College, Bankura, West Bengal, India

${ }^{3}$ Department of Community Medicine, Bankura Sammilani Medical College, Bankura, West Bengal, India

${ }^{4}$ Department of Pathology, Murshidabad Medical College, Murshidabad, West Bengal, India
\end{abstract}

Received: 08 October 2016

Accepted: 03 November 2016

\section{*Correspondence:}

Dr. Aditya Prasad Sarkar,

E-mail: dradityaprasadsarkar@gmail.com

Copyright: (c) the author(s), publisher and licensee Medip Academy. This is an open-access article distributed under the terms of the Creative Commons Attribution Non-Commercial License, which permits unrestricted non-commercial use, distribution, and reproduction in any medium, provided the original work is properly cited.

\section{ABSTRACT}

Background: Among Indian women cancers of cervix and breast account for a very large proportion of malignancies. Majority of the cancer patients present themselves to the doctor at an advanced and incurable stage. Screening for cervical cancer can be done by Pap test which is a very simple and inexpensive test. Early detection and treatment of pre-cancerous conditions and cancers provide the best possible protection against cancer for the individual and the community.

Methods: A descriptive study with cross-sectional design was conducted in the laboratory of the Department of Pathology at Bankura Sammilani Medical College, Bankura in West Bengal during January 2014 to December 2014. Analysis of cervical cytology was done for neoplastic cells.

Results: Out of 288 smears $8.3 \%$ samples were unsatisfactory, $77.9 \%$ were without epithelial cell abnormality while $13.8 \%$ were abnormal comprising of atypical squamous cells of undetermined significance (ASCUS) $1.4 \%$, low grade squamous intra-epithelial lesion (LSIL) $8.3 \%$, had high grade squamous intra-epithelial lesion (HSIL) $3.5 \%$ and squamous cell carcinoma, and post-radiation effect $0.3 \%$ each. Abnormality of smear was significantly associated with age group and religion of the cases $(\mathrm{p}<0.05)$.

Conclusions: Majority of the cases cervical cytology were reported to be without any epithelial cell abnormality followed by LSIL. Age and religion were significantly associated with the abnormality of smears.

Keywords: Cytology, Pap smear, Tertiary care hospital

\section{INTRODUCTION}

Cervical cancer in the females can be prevented by early detection of the precursor lesions which can be easily identified in cervicovaginal preparations. Eradication of such lesions can prevent the occurrence of invasive cancer. It has been repeatedly documented that invasive carcinoma of the uterine cervix, regardless of type, develops from precursor lesions or abnormal surface epithelium, which, in its classic form, is known as carcinoma in situ (International Stage O). The precursor lesions do not produce any specific alterations of the cervix visible to the naked eye. Therefore, before the introduction of cervicovaginal cytology and colposcopy, these lesions were a rarity and their discovery was incidental in biopsies of the cervix and in hysterectomy specimens. ${ }^{1}$

Since the introduction of mass screening by smears, and with accumulated experience, it has been shown that these lesions are quite common. The investigations of the precursor lesions is facilitated by the accessibility of the 
cervix to clinical examination and inspection by the colposcope and the ease of cytologic and histologic sampling that could be subjected, not only to microscopic scrutiny, but also to cytogenetic and molecular biologic analysis. The success of these programs has been confirmed because, over the past half century, the rate of invasive cancer of the uterine cervix has been reduced by about $70 \%$ in the United States and other developed countries (summaries in Koss, 1989; Cannistra and Niloff, 1996). In developing countries, however, cancer of the cervix remains a common disease with a high mortality rate. ${ }^{1}$

The Pap test is considered by many to be the most costeffective cancer reduction program ever devised. Credit for its conception and development goes to George N.Papanicolaou, an anatomist and Greek immigrant to the United States. In 1928 he reported that malignant cells from the cervix can be identified in vaginal smears. Later, in collaboration with the gynecologist Herbert Traut, who provided him with a large number of clinical samples, Papanicolaou published detailed descriptions of preinvasive cervical lesions. Pathologists and physicians initially greeted this technique with skepticism, but by the late 1940s Papanicolaou's observations had been confirmed by others. The Canadian gynecologist J. Ernest Ayre suggested taking samples directly from the cervix with a wooden spatula rather than from the vagina with a pipette as originally described by Papanicolaou. Eventually, cytologic smears were embraced as an ideal screening test for preinvasive lesions, which, if treated, would be prevented from developing into invasive cancer. $^{2}$

Cancer of the cervix is a global health problem, comprises approximately $12 \%$ of all cancers among women globally. Incidence and mortality of cancer cervix in world is 530232 and 275008 per year while in India it is 134420 and 72825 per year respectively. ${ }^{3}$ With this background the study was conducted to study the sociodemographic characteristics of the adult women attending the Pathology Department of Bankura Sammilani Medical College and Hospital, West Bengal for cervical pap smear examination, to assess the cervical smears and to identify any factor(s) associated with abnormal pap smear.

\section{METHODS}

It was a descriptive study with cross-sectional design. The study was conducted in the laboratory of the Department of Pathology of Bankura Sammilani Medical College and Hospital in West Bengal during one year i.e. from January 2014 to December 2014.The samples were examined from those female patients who were referred by the Department of Gynaecology of the Medical College for abnormal cervical discharge. The samples were collected with the help of a wooden or plastic spatula called Ayre's spatula .The spatula after introduction into the vagina was rotated through $360^{\circ}$ to get material from ectocervix and squamocolumnar junction. Smears were made on glass slides from the spatula. Then the smear was immersed directly into a Coplin jar filled with $95 \%$ ethanol for fixation. This part of the collection was done by the gynaecologists and the glass slides were sent to the Pathology Department, where the smears were stained by Leishman and Giemsa method and examined under light microscope. The reporting was done following Bethesda method 2001. ${ }^{4}$

\section{RESULTS}

Out of 288 cases majority were in 31-40 years age group $(28.1 \%)$ followed by $41-50$ years $(26.4 \%)$, whereas women aged 71 years or more contributed only $2.1 \%$. (Table 1)Women of More than $50 \%$ of the cases were comprised of women of 31-50 years. Majority of the cases were Hindu (91.3\%) while only $8.7 \%$ were Muslim (Table 2).

Table 1: Distribution of cases according to age $(n=288)$.

\begin{tabular}{|lll|}
\hline Age $($ yrs $)$ & Number & Percentage \\
\hline $\mathbf{3 0}$ & 75 & 26.0 \\
\hline $\mathbf{3 1 - 4 0}$ & 81 & 28.1 \\
\hline $\mathbf{4 1 - 5 0}$ & 76 & 26.4 \\
\hline $\mathbf{5 1 - 6 0}$ & 31 & 10.8 \\
\hline $\mathbf{6 1 - 7 0}$ & 19 & 6.6 \\
\hline $\mathbf{2 7 1}$ & 6 & 2.1 \\
\hline Total & 288 & 100.0 \\
\hline
\end{tabular}

Table 2: Distributions of the cases according to religion $(\mathbf{n}=\mathbf{2 8 8})$.

\begin{tabular}{|lll|}
\hline Religion & Number & Percentage \\
\hline Hindu & 263 & 91.3 \\
\hline Muslim & 25 & 8.7 \\
\hline Total & 288 & 100.0 \\
\hline
\end{tabular}

Table 3: Distribution of cases according to type of lesion $(\mathbf{n}=\mathbf{2 8 8})$.

\begin{tabular}{|lll|}
\hline Type of cytology & Number & Percentage \\
\hline Unsatisfactory smear & 24 & 8.3 \\
\hline NILM* & 224 & 77.9 \\
\hline Abnormal smear & 40 & 13.8 \\
\hline ASCUS & 4 & 1.4 \\
\hline LSIL & 24 & 8.3 \\
\hline HSIL & 10 & 3.5 \\
\hline Post-radiation & 1 & 0.3 \\
\hline SCC & 1 & 0.3 \\
\hline
\end{tabular}

* Negative for intraepithelial lesion or malignancy

Smears were subdivided into three general categories i.e. unsatisfactory, Normal or abnormal. Out of total 288 cervical smears collected $24(8.3 \%)$ were unsatisfactory 
(Table 3). Examination of 266 satisfactory samples revealed that in $224(77.9 \%)$ smears no intraepithelial cell lesion or malignancy (NILM) was found. On the other hand, $40(13.8 \%)$ of the cervical smears were abnormal. Abnormal smears were subdivided into ASCUS (atypical squamous cell of unknown significance), LSIL (low grade squamous intra epithelial lesion) and HSIL (high grade squamous intra epithelial lesion), SCC (squamous cell carcinoma) and post radiation. Out of the abnormal smears, majority were LSIL $24(8.3 \%)$, followed by HSIL $10(3.5 \%)$, ASCUS $4(1.4 \%)$ and $0.3 \%$ was contributed by post-irradiation and squamous cell carcinoma each.

Table 4: Distribution of cases according to age and type of cervical cytology $(n=288)$.

\begin{tabular}{|lllllllll|}
$\begin{array}{l}\text { A ge group } \\
\text { (years) }\end{array}$ & $\begin{array}{l}\text { Type of cytology } \\
\text { Unsatisfactory }\end{array}$ & NILM & ASCUS & LSIL & HSIL & SCC & $\begin{array}{l}\text { Post- } \\
\text { irradiation }\end{array}$ \\
\hline$\leq 30$ & $5(6.7)$ & $60(80)$ & $0(0.0)$ & $7(9.3)$ & $3(4.0)$ & $0(0.0)$ & $0(0.0)$ & 75 \\
\hline $31-40$ & $6(7.4)$ & $63(77.8)$ & $1(1.2)$ & $10(12.3)$ & $1(1.2)$ & $0(0.0)$ & $0(0.0)$ & 81 \\
\hline $41-50$ & $7(9.2)$ & $58(76.3)$ & $2(2.6)$ & $5(6.6)$ & $3(3.9)$ & $0(0.0)$ & $1(1.3)$ & 76 \\
\hline $51-60$ & $4(12.9)$ & $25(80.6)$ & $0(0.0)$ & $0(0.0)$ & $1(3.2)$ & $1(3.2)$ & $0(0.0)$ & 31 \\
\hline $61-70$ & $1(5.3)$ & $15(78.9)$ & $1(5.3)$ & $1(5.3)$ & $1(5.3)$ & $0(0.0)$ & $0(0.0)$ & 19 \\
\hline$\geq 71$ & $1(16.7)$ & $3(50.0)$ & $0(0.0)$ & $1(16.7)$ & $1(16.7)$ & $0(0.0)$ & $0(0.0)$ & 6 \\
\hline Total & $24(8.3)$ & $224(77.8)$ & $4(1.4)$ & $24(8.3)$ & $10(3.5)$ & $1(0.3)$ & $1(0.3)$ & 288 \\
\hline
\end{tabular}

* Figures in the parentheses indicate percentage.

Table 5: Distribution of cases according to age and type of lesion $(n=264)$.

\begin{tabular}{|llll|}
\hline $\begin{array}{l}\text { Age group } \\
\text { (in years) }\end{array}$ & \multicolumn{2}{l|}{ Cervical cytology } & Total \\
\hline $\mathbf{5 0}$ & NILM & Abnormal & \\
\hline $\mathbf{5 1}$ & 181(80.8) & 22(19.2) & 203 \\
\hline Total & $224(10)$ & $18(78.8)$ & 61 \\
\hline
\end{tabular}

* Figures in the parentheses indicate percentage.

Table 4 reveals that NILM smears were majority in all age groups. LSIL was mostly in 51-60 years age group $(22.7 \%)$ while HSIL was mostly found among women aged 71 years or more $(16.7 \%)$. One case of postradiation was found in 61-70 years age group while the lone case of cervical carcinoma was found in 51-60 years age group.

Table 6: Distribution of cases according to religion and type of lesion $(n=264)$.

\begin{tabular}{llll|}
\multirow{2}{*}{ Religion } & \multicolumn{2}{l}{ Cervical cytology } & Total \\
\cline { 2 - 4 } Hindu & NILM & Abnormal & \\
\hline Muslim & $11(61.1)$ & 34(13.8) & 246(100.0) \\
\hline Total & $223(100.0)$ & $41(100.0)$ & $18(100.0)$ \\
\hline
\end{tabular}

* Figures in the parentheses indicate percentage.

Abnormality of cervical smear was significantly associated with the age group of the women where the $\mathrm{p}$ value $<0.05\left(\chi^{2}=7.18\right.$, d.f. $\left.=1\right)($ Table 5$)$. The abnormality of cervical smear was also significantly associated with the religion of the women where the $\mathrm{p}$ value $<0.05\left(\chi^{2}=\right.$ 8.0, d.f.=1) $($ Table 5).

\section{DISCUSSION}

In this study it was observed that among 288 patients, women from all age groups between 20 years to 90 years were present. All of them attended Gynaecology and Obstetrics OPD due to some complaints of reproductive tract. Thus routine screening among women was not practiced.

The present study revealed that NILM was $20.5 \%$ while it was 29.0 in a study at Western maharashtra ${ }^{5}$ while it was $16.96 \%$ in a study at Pune. ${ }^{3}$ But a study at Guwahati reported NLIM of more than $80 \% .^{6}$ ASCUS was only $1.3 \%$ in the present study while it was slightly more in Pune study and much more in Guwahati study. ${ }^{5,6}$ LSIL was reported to be in $8.3 \%$ smears. It was less in Pune and Guwahati while it was much more in Maharashtra. HSIL was present in $3.5 \%$ cases whereas it was less in Pune and Maharashtra study but much more in Guwahati study. ${ }^{3,5,6}$

Proportion of cases with cervical carcinoma was more in a study by Bamanikar A S et al and Deshpande J D while much more in the study by Sarma $U$ et al.The type of cytology was statistically associated with age group of women. Similar finding was found in the study by Sarma $\mathrm{U}$ at Guwahati. ${ }^{6}$

Jason Poole, Head of Cancer Analysis at Trent Cancer Registry summarizes the key findings: "There has been 
an increase in the incidence of cervical cancer in women aged under 35 since the late 1990s. Over this time there has also been a steady fall in the coverage in women of this age group. "Increasing coverage in these age groups will be important to stop this trend. While screening older women leads to a substantial reduction in cervical cancer, screening in women aged $20-24$ has been shown to have little or no impact on rates of invasive cervical cancer at ages $25-29.7$ Indeed, the upward trend in incidence rates began from 2000 following several years of decline in coverage." Jason concludes: "It is clear that as screening coverage decreases in younger women, incidence of cervical cancer rises. It is important that the recent upward trend in screening coverage continues, so that the number of women who develop cervical cancer can be reduced. I would hope that this message gets through to all women and young women in particular, to encourage them to take up cervical screening when invited."7

The incidence of carcinoma of the cervix is very low in women aged less than 25 years, but then begins to climb. However, in an extension of the British Columbia cohort study, the incidence of carcinoma in situ at age 20-24 was of the order of 16 per 100000 , encouraging a national workshop in Canada to recommend that screening should start at the age of 20 years. For developing and some middle income countries, in order to maximize use of resources, and given the infrequency of cervical cancer below the age of 35 years, it is generally recommended to start screening at 35 years and only extend screening to younger ages when resources permit (WHO, 1986). It has been pointed out that age is the most important risk factor for cervical cancer and that screening should aim to target high-risk women. A good guide would be to take the age at the beginning of the rise in incidence of cervical cancer and begin screening five years before this age. In most countries, this would be at about 30-35 years of age.$^{8}$

Thus we can conclude that majority of the samples of cervical discharge $(60 \%)$ received by the Pathology Department from Gynaecology and Obstetrics OPD were negative for any intra-epithelial lesion and reported as NILM. Cases which were reported as positive for intraepithelial lesion were mostly low grade squamous intraepithelial lesion(LSIL) $(8.3 \%)$ followed by high grade lesions(3.5\%). Abnormality of smears was significantly associated with the age group and religion of the cases. Routine screening for cervical cancer by pap smear should be religiously followed to reduce its incidence.

\section{CONCLUSION}

Taking into the consideration of endocrine and age specific changes, postmenopausal women face sexual dysfunctions. Physicians should provide them with the opportunity to express their thoughts, offering them alternatives for both evaluation and treatments. It is mandatory to increase recognition and perceptions of female sexual dysfunction and dismiss taboo and improper thoughts which will help in the better management of patients allowing them to lead good quality of life.

\section{ACKNOWLEDGEMENTS}

Authors would like to thanks to Prof. (Dr.) Swapan Pathak, Head of the Department, Department of Pathology, Bankura Sammilani Medical College, Bankura, West Bengal, India.

Funding: No funding sources

Conflict of interest: None declared

Ethical approval: Not required

\section{REFERENCES}

1. Leopold G, Myron R. Koss' Diagnostic Cytology and Its Histopathologic Bases. 5th.ed. New York; Lippincott Williams and Williams; 2006.

2. Edmund S, Cibas Barbara S. Cytology Diagnostic Principles and Clinical Correlates. Chapter 1. $3^{\text {rd }}$ ed. China; Elsevier; 2009.

3. Bamanikar AS, Baravkar DS, Chandanwale SS. Study of Cervical Pap Smears in a Tertiary Hospital. Indian Medical Gazette. 2014. pp. 250-254.

4. Solomon D, Davey D, Kurman R, Moriarty A, O'Connor D, Prey M et al. The 2001 Bethesda System terminology for reporting results of cervical cytology JAMA. 2002;287:2114-9.

5. Deshpande JD, Phalke BD, Phalke VD. Profile of cervical smear cytology in women attending Health center in rural area of western Maharashtra IJBAR. 2013;3(3):205-8.

6. Sarma U, Mahanta J, Talukdar KL. Reporting of cervical cytology in women attending a tertiary hospital in Guwahati, India : some demographic profiles The Clarion. 2013;2(1):13-7.

7. NHS Cervical Screening Programme Annual Review 2011.

8. IARC Handbooks of Cancer Prevention Chapter 4 (Efficacy of screening).Volume 10. Lyon; IARC Press; 2005.

Cite this article as: Bhattacharyya NB, Naga D, Sarkar AP, Mandy S, Das PC. Cytological profile of Pap smears in a tertiary care hospital of West Bengal, India. Int J Reprod Contracept Obstet Gynecol 2016;5:4397-4400. 